\title{
AIR TRANSPORT, INSECTS AND DISEASE
}

\begin{abstract}
By DR. A. D. ImMS, F.R.S.
$\mathrm{M}$ R. F. G. SAREL WHITFIELD has recently issued a comprehensive article on air transport, insects and disease (Bull. Entomol. Res., 30, $365-442 ; 1939$ ). The discovery by Shannon in 1930 of the presence of Anopheles gambioe, an insect native to Africa, in the city of Natal, Brazil, and its subsequent spread, directed special attention to the carriage of disease-bearing insects by aeroplanes. Whether $A$. gambice was actually transported in a surface vessel or in an aircraft will probably never be known, but, as the result of its entry and subsequent spread, more than 90 per cent of the population around Natal were infected with malaria in 1938. The indexes of malaria-infected mosquitoes are said to be the highest in the history of malaria. The introduction of $A$. gambice into South America seems to have had the disquieting results, just referred to, because possibly the native population has very little power of resistance to the African strain of the disease carried by the mosquito.

The situation as regards yellow fever is potentially far more serious than that concerning malaria. Shannon, Whitman and Franca in 1938 made a significant contribution to what is known of the vectors of yellow fever. They produced positive evidence of the mosquitoes Aëdes leucocelcenus and Homogogus capricorni being concerned in the transmission of jungle yellow fever in Brazil. Until this discovery, evidence of any mosquito other than $A \ddot{e} d e s$ cegypti being implicated in the transmission of yellow fever was furnished solely on the results of laboratory experimentation. The aspect of most importance with regard to aerial transport, arising out of recent research on yellow fever epidemiology, seems to be

the discovery of vast areas in Africa and South America where the disease prevails in epidemic or endemic form. It is obviously of prime importanoe that aireraft operating within and from Africa and South America should be maintained free from all insects. Mr. Whitfield points out that the proposed reserve Empire war route across Africa to India and Australia will present an urgent problem in this connexion, and that it would be unwise to inaugurate such a service until the proper control of insects in aircraft has been achieved. In view also of the proved existence of considerable inseet populations in the upper air, the question of the possibility of aircraft collecting insects while in flight arises. The ability of insects to survive air transit is another problem. Aëdes cegypti, for example, has been proved to be able to endure a journey of at least 9,580 miles in length and of $6 \frac{1}{2}$ days duration.

Diptera are overwhelmingly the commonest insects found in aircraft. Species of Musca are very frequent and also many kinds of mosquitoes. The control of insects in aircraft is a difficult subject. As $\mathrm{Mr}$. Whitfield remarks, it involves the co-operation of the entomologist, the chemist and the engineer, an airline operating company and a commercial aircraft manufacturer. Such joint approach to the problem, he holds, is essential if progress is to be made. No adequate and reliable method of control of insects in aircraft has yet been devised: the problem of controlling insect invaders of aerodromes needs also the fullest attention. Little will be gained, the author adds, from further research upon insects found in aircraft-the real problem being the effective means for their destruction.
\end{abstract}

\section{THE ROTHAMSTED EXPERIMENTAL STATION}

\section{By E. J. RoBERTS}

$\mathrm{T}$ HE annual reports of the Rothamsted Experimental Station are of more than ordinary interest to farmers and research workers. The amount and variety of the fundamental investigations carried out in the laboratories, linked with the field work not only at the Rothamsted and Woburn farms, but also at a number of commercial farms scattered over England, give these reports a character and importance of their own. The improvements in the technique of field experimentation, evolved at the statistical department, have not only given more accuracy to the usual trials, but also have widened the scope of investigations by making it possible to detect small differences, and to measure, for example, the interaction effects of certain manures.

In the report for $1938^{*}$, published recently, an account is given of the experiments on wheat, including those on the continuous growing of this

* Rothamsted Experimental Station, Harpenden. Report for 1938 (Harpenden: Lawes Agricultural Trust.) 58. crop, and those on the value of leys, green manures, and fallows for preceding the wheat crop. 'The experiment on the continuous growing of wheat has now been in progress for nearly a hundred years, and it is interesting to note that the land has not become what might be termed 'wheat-sick'; the main difficulty has been in the suppression of weeds rather than in the actual growth of wheat. This conclusion is important at the present time. Why, it is asked, when these experiments prove clearly that wheat can be grown continuously on the same land, should difficulties arise when the erop is grown for a few years in succession on certain mechanized farms? An explanation is offered to the effect that the nature of the soil is responsible. Wheat is a heavy-land crop, and, on the heavy Broadbalk soil, the crop remains healthy; diseases and pests are present; but they do little damage. The lighter soils, however, especially the light chalky soils on which many mechanized farms are situated, are more liable to 